\title{
Doctors' knowledge of the doses and risks of radiological investigations performed in the emergency department
}

\author{
Rashid A. Barnawi, MBBS, Weaam M. Alrefai, MBBS, Faris Qari, MBBS, Ahmed A. Aljefri, MBBS, \\ Sarah K. Hagi, PhD, Mawya Khafaji, MSc, PhD.
}

\begin{abstract}
الأهداف: مع الاستخدام المتزايد للفحوصات الإشعاعية في ممارسة

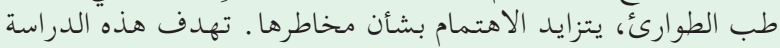

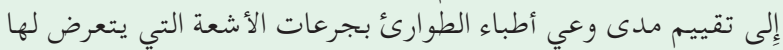
المرضى والمخاطر المصناحبة مئ.

الطريقة: تم توزيع استبيان على أطباء من تخصصصات مختلفة

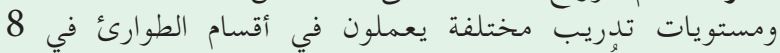

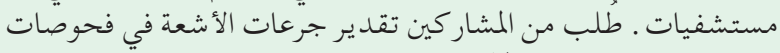

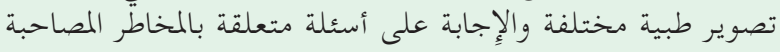

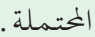

النتائج : ما مجموعه 171 طبيب أجابوا على الاستبيانات . كان معدل

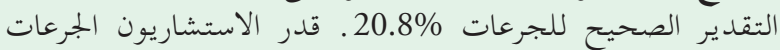

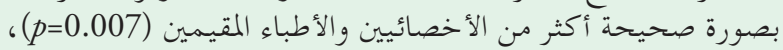

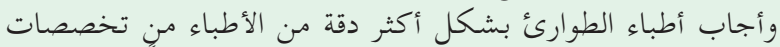

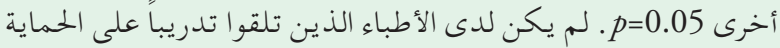

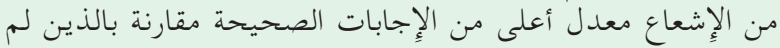
يتلقوا تدريب (

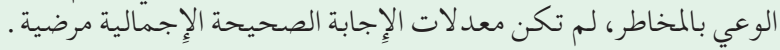

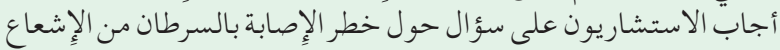

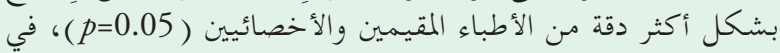

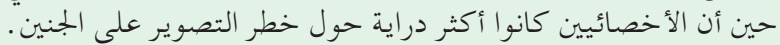

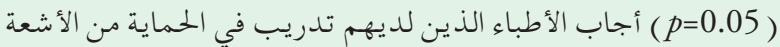

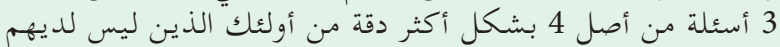

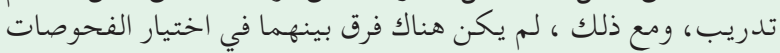

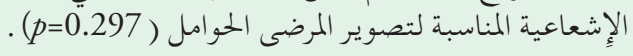

الحناتمة: توضح هذه الدراسة أن الأطباء العاملين في قسم الطوارىء

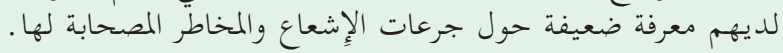
هذه الملاحظة تستد لدعي اهتمام عاجل .
\end{abstract}

Objectives: To assess emergency doctors' knowledge of radiation exposure doses and risks, as the increasing use of radiological investigations in emergency medicine practice is very concerning because of the associated risk of cancer.
Methods: Doctors from different specialties and with different levels of training working in emergency departments of 8 hospitals in Jeddah, Kingdom of Saudi Arabia, filled out a questionnaire. Participants estimated the radiation doses of different imaging modalities and answered questions regarding possible associated risks.

Results: One hundred seventy-one doctors returned completed questionnaires. The overall correct dose estimation rate was $20.8 \%$. Doses were more correctly estimated by consultants versus specialists and residents $(p=0.007)$, and by emergency physicians versus doctors from other specialties $(p=0.05)$. The correct answer rate was insignificantly higher among doctors with formal training on radiation protection $(p=0.065)$. The overall correct answer rate was unsatisfactory for 4 questions assessing physicians' knowledge of risks. Questions about the lifetime risk of cancer due to ionizing radiation were more correctly answered by consultants versus residents and specialists $(p=0.05)$. Specialists were more knowledgeable about the risk of imaging on fetuses $(p=0.05)$. Doctors with formal training answered 3 out of 4 questions more correctly than doctors without formal training, but no difference existed between them regarding imaging modalities, that they selected for pregnant patients $(p=0.297)$.

Conclusion: Doctors working in emergency departments had poor knowledge about radiation doses and risks. This issue warrants urgent attention.

Saudi Med J 2018; Vol. 39 (11): 1130-1138 doi: 10.15537/smj.2018.11.23091

From the Department of Radiology (Barnawi, Hagi, Khafaji), Faculty of Medicine; from the Faculty of Medicine (Alrefai), King Abdulaziz University, Jeddah, from the Department of Radiology (Qari), Armed Forces Hospital, Southern Region, and from the Department of Emergency (Aljefri), King Saud Medical City, Riyadh, Kingdom of Saudi Arabia.

Received 29th July 2018. Accepted 17th October 2018.

Address correspondence and reprint request to: Dr. Rashid A. Barnawi, Department of Radiology, Faculty of Medicine, King Abdulaziz University, Jeddah, Kingdom of Saudi Arabia. E-mail: rbrnawy@kau.edu.sa ORCID ID: orcid.org/0000-0002-3656-222 
Tn an emergency department (ED), different diagnostic imaging investigations that use ionizing radiation are increasingly used to diagnose a variety of diseases and injuries. ${ }^{1}$ In particular, the use of computed tomography (CT) scanning is increasing annually. ${ }^{2}$ This imaging modality is associated with greater radiation doses, compared with conventional x-ray imaging. ${ }^{1-3}$ In an emergency setting, one in 7 patients undergoes CT scanning, which accounts for $25 \%$ of all CT scans in the United States of America. ${ }^{3}$ Despite the immense benefit of these radiological investigations, there are dose-related risks, especially a risk of developing cancer, given that ionizing radiation is an established carcinogen. ${ }^{1-3}$ It has been estimated that radiation doses in diagnostic CT's are similar to those delivered to Japanese survivors of atomic bombs, many of whom had a statistically significant increased risk of cancer. ${ }^{4}$ Children particularly have a higher lifetime risk of developing cancer, compared with adults, because their growing tissues are more susceptible to ionizing radiation, and they have a longer span of time to develop cancer. ${ }^{2,5,6}$ Therefore, it is essential for ED doctors who request radiological investigations to know radiation doses and the risks of these requested studies, and to be able to determine whether they are required. ${ }^{7}$ In addition, according to the international commission on radiological protection (ICRP) report, knowledge of the health effects of ionizing radiation is of utmost importance. ${ }^{8}$

In Kingdom of Saudi Arabia, insufficient data exist regarding the current level of knowledge among emergency physicians. However, several studies worldwide have demonstrated that doctors working in EDs have inadequate knowledge of the ionizing radiation risks associated with the radiological investigations they order. ${ }^{1-3,7}$ In Turkey, Günalp et al, ${ }^{1}$ conducted a study in the ED of the Ankara University School of Medicine in Ankara, Turkey, that included 300 interns, resident doctors, and radiographers. It aimed to assess their knowledge of radiation risks and doses used in different imaging modalities. Only $42.1 \%$ of the radiation doses delivered by these imaging modalities were estimated correctly. A large proportion of participants underestimated the doses and risks associated with the imaging modalities. Another study by Keijzers et al, ${ }^{2}$ which was conducted in the EDs of 2 hospitals in Queensland, Australia, investigated 97 emergency

Disclosure. Authors have no conflict of interests, and the work was not supported or funded by any drug company. doctors' understanding of radiation risks. Their overall knowledge score was $40 \%$. There was no significant difference between the senior doctors' score (42\%) and the junior doctors' scores (39\%). In addition, 78\% of the doctors underestimated the lifetime risk of fatal cancer attributed to a single abdominal CT scan. ${ }^{2}$ In previous studies, it is vitally important to gain an insight into the current level of knowledge about ionizing radiation doses and risks among physicians in Kingdom of Saudi Arabia, and to implement measures to address any lack of knowledge. The aim of this study was to assess the knowledge of radiation doses and risks among doctors working in EDs in the city of Jeddah, Kingdom of Saudi Arabia, and to suggest measures by which this knowledge, if insufficient, could be improved.

Methods. In this prospective observational study, a validated questionnaire was distributed to all emergency doctors and doctors from other specialties who were on rotation in the ED and who agreed to participate in our study. This study included 8 different secondary care hospitals, tertiary care hospitals, and university hospitals in Jeddah, Kingdom of Saudi Arabia. These hospitals were selected because of the flow of patients and the availability of CT and magnetic resonance imaging (MRI) scans. The questionnaire was distributed over a 2-month period from June-August 2017. These hospitals included public and private hospitals. On distributing the questionnaires, participants were asked to anonymously complete the questionnaires immediately and return them after completing them so they would not have the time to search for correct answers through an internet search. They were also asked to remain in the room until they completed all answers. There was no time limit during which they had to complete the questionnaire. The paper question naires were distributed after obtaining ethical approval from the research ethics committee of the faculty of medicine, King Abdulaziz University in Jeddah, Kingdom of Saudi Arabia. Participation was entirely voluntary.

Questionnaire. We used a validated questionnaire obtained from the Günalp et al, ${ }^{1}$ study. As in our study, the Günalp study focused on assessing physicians' knowledge of radiation doses and radiation risks in children and adults. The questionnaire comprised 18 questions and had 3 parts. The first part obtained information about the participants' demographics. It included questions about their specialty; level of training, which was resident doctor (namely, "trainee doctor"), board-certified specialist, or consultant; and whether they had formal training on radiation protection. We also asked questions regarding the 
average number of patients seen within an 8-hour ED shift and the average number of CT/X-ray examinations ordered within an 8-hour ED shift. The second part tested the participants' knowledge of ionizing radiation doses associated with different radiological investigations. We asked the participants to estimate the radiation dose associated with 7 radiological modalities that use ionizing radiation and 2 modalities that do not use ionizing radiation (namely, ultrasonography [US] and MRI). The effective doses of radiation associated with various imaging modalities and the equivalent number of chest X-ray scans that release the same doses are presented in Appendix 1. Participants had to choose the range of equivalent number of chest X-ray scans that was considered acceptable. We obtained correct answers to these questions from the united nations scientific committee on the effects of atomic radiation (UNSCEAR) report. ${ }^{9}$ In the third part of the questionnaire, the respondents' knowledge was evaluated regarding the lifetime risk of cancer due to ionizing radiation, their knowledge regarding the selection of imaging modalities for pregnant patients, and their knowledge about the risks to the fetus. We asked the participants whether they would inform their patients about the risks of radiation before undergoing a procedure.

Statistical analysis. We used the Chi-square test to evaluate categorical variables, while continuous variables were evaluated using both the independent t-test and one-way analysis of variance test. Differences with $p$-values $\leq 0.05$ were considered statistically significant. We analyzed the data using statistical package for the social sciences (SPSS), version 23 (IBM Corp., Armonk, NY, USA).

Results. One hundred seventy-one doctors completed the questionnaire. Most 58\% respondents were emergency physicians, and most $64 \%$ of the 171 doctors were resident doctors. Only approximately $20 \%$ of the participants had received formal training on radiation protection. The characteristics of the participants are described in Table 1 . The mean \pm standard deviation (SD) of patients they saw in a typical 8-hour ED shift was $26 \pm 35$ patients, and the mean \pm SD of $\mathrm{CT} / \mathrm{x}$-ray orders they requested in a typical 8-hour shift was $8 \pm 7$.

The overall average correct dose estimation rate was $20.8 \%$, whereas the overall dose-underestimation rate was $28.6 \%$ and the dose-overestimation rates was $10 \%$. However, most participants answered "I don't know" (40.6\%). The numbers and percentages of correct answers, underestimations, overestimations and "I don't
Table 1 - Demographic and characteristics of 171 participants.

\begin{tabular}{lc}
\hline Variables & $\mathbf{n}(\%)$ \\
\hline Specialty & \\
Emergency physician & $99(58.2)$ \\
Medicine & $21(12.4)$ \\
Surgery & $21(12.4)$ \\
$\quad$ Pediatrics & $14(8.2)$ \\
Other specialties & \\
Obstetrics and gynecology & $15(8.8)$ \\
ENT & \\
Orthopedics & \\
Ophthalmology & \\
Level of training & \\
Resident & $109(63.7)$ \\
Specialist & $40(23.5)$ \\
Consultant & $21(12.4)$ \\
Training on radiation protection & \\
Yes & $34(19.9)$ \\
No & $137(80.1)$ \\
Patients seen during a typical 8-hour emergency & \\
department shift & \\
Mean \pm SD & $25.6 \pm 35.3$ \\
Median no. (IQR) & $10(5-30)$ \\
CT/x-ray orders requested during a typical 8-hour \\
emergency department shift \\
Mean \pm SD \\
Median no. (IQR) \\
\hline ENT - ear, nose and throat, IQR - interquartile range, CT - computed \\
$\quad$ tomography \\
\hline
\end{tabular}

know" answers for each imaging modality separately are shown in Table 2.

Consultants were significantly more knowledgeable than specialists and residents, and had an overall correct answer rate of $32.4 \%$, compared with $22 \%$ for specialists and $18.3 \%$ for residents $(p=0.007)$. Figure 1 shows the overall correct dose estimation rate for the different specialties. Emergency physicians estimated the doses significantly more correctly than the doctors from other specialties $(p=0.05)$. The emergency physicians' correct answer rate was $50.8 \%$. By contrast, there was no significant statistical difference in correct dose estimation between doctors who received formal training on radiation protection $(25.2 \%)$ and doctors who did not receive this training $(19.7 \% ; p=0.065)$.

Table 3 presents the participants' answers to questions assessing their knowledge of the risks of radiation. Thirty-nine percent of the doctors correctly answered that a one-time abdominal CT in childhood increases the lifetime risk of developing cancer. We asked participants whether they notified their patients about the potential adverse effects of radiation before ordering the examination, and 63\% answered "yes". With regard to their behavior when ordering a 
Table 2 - Estimations of radiation doses used in various imaging modalities.

\begin{tabular}{|c|c|c|c|c|}
\hline Imaging modality & Correct & $\begin{array}{c}\text { More than } \\
\text { the equivalent } \\
\text { number of chest } \\
\text { x-rays }\end{array}$ & $\begin{array}{l}\text { Less than the } \\
\text { equivalent } \\
\text { number of chest } \\
\text { x-rays }\end{array}$ & $\begin{array}{c}\text { "Don't know" } \\
\text { response }\end{array}$ \\
\hline Cranial x-ray & $80(46.8)$ & $12(7.0)$ & $5(2.9)$ & $74(43.3)$ \\
\hline Pelvic x-ray & $23(13.5)$ & $7 \quad(4.2)$ & $71(41.5)$ & $70(40.9)$ \\
\hline Abdominal US & $76(45.0)$ & $27(15.9)$ & 0 & $66(39.1)$ \\
\hline Abdominal x-ray & $21(12.4)$ & $14 \quad(8.2)$ & $68(40.0)$ & $67(39.4)$ \\
\hline Chest CT & $18(10.5)$ & $13 \quad(7.6)$ & $69(40.4)$ & $71(41.5)$ \\
\hline Abdominal CT & $13 \quad(7.6)$ & 0 & $85(50.0)$ & $72(42.4)$ \\
\hline Abdominal MRI & $56(33.0)$ & $47(27.6)$ & 0 & $67(39.4)$ \\
\hline Pelvic CT & $9 \quad(5.2)$ & 0 & $93(54.4)$ & $69(40.4)$ \\
\hline Cranial CT & $23(13.5)$ & $33(19.2)$ & $47(27.5)$ & $68(39.8)$ \\
\hline
\end{tabular}

Values are presented by number and percentage (\%), US - ultrasound, CT - computed tomography, MRI - magnetic resonance imaging.

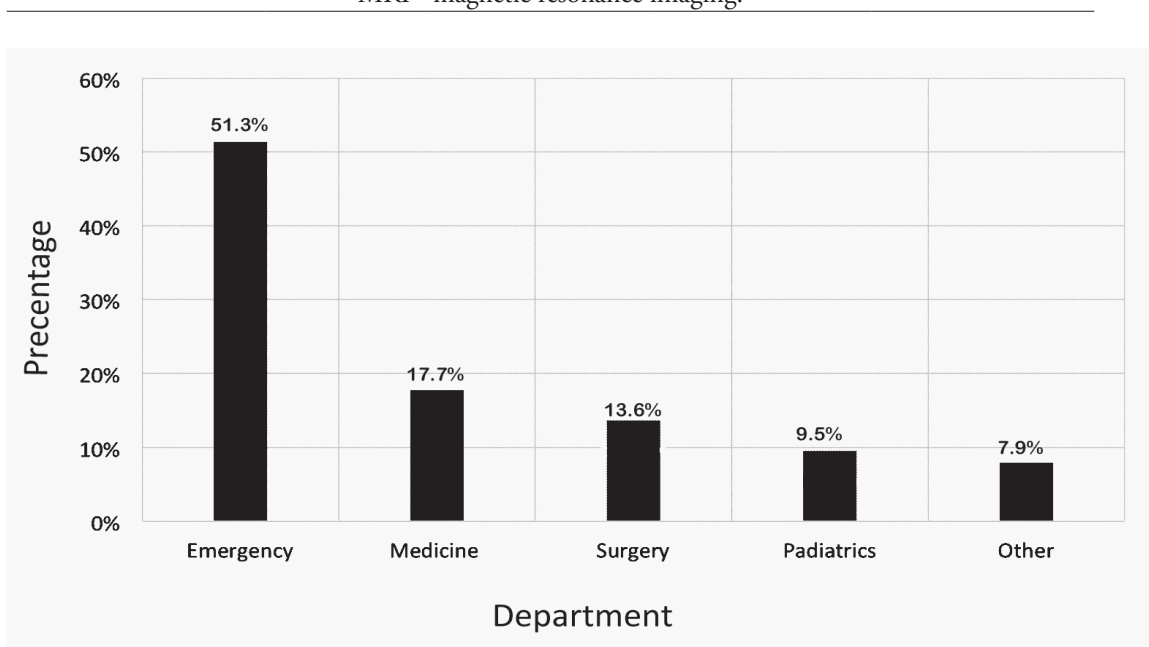

Figure 1 - The correct dose estimation rate by specialty.

diagnostic radiological exam for a pregnant patient, $33 \%$ of doctors correctly answered that they observed the pros and cons of such an examination, notified the patient about the potential outcomes, and requested that a lead vest be worn by the patient. With regard to the question assessing their knowledge about the risk of radiation for fetus, 37\% of doctors correctly answered that the study with the lowest risk for the fetus is the chest CT scan, as opposed to lumbar and abdominal $\mathrm{x}$-ray and pelvic and abdominal CT scans.

Consultants (57\%) answered the question about the lifetime risk of cancer due to ionizing radiation significantly more correctly than specialists (36.8\%) and residents $(35.9 \%)(p=0.05)$. However, specialists (47.4\%) were more knowledgeable about the risk of imaging on a fetus than were consultants $(28.6 \%)$ and residents $(34.3 \%)(p=0.05)$. However, there was no statistically significant difference between them in their answers to questions about informing their patients about the risks of radiation $(p=0.985)$ and their behavior in the selection of imaging modalities for pregnant patients $(p=0.11)$ (Figure 2). Doctors who had formal training on radiation protection were significantly more knowledgeable about the lifetime risk of cancer due to ionizing radiation $(p=0.028)$ and the risk of imaging on fetus $(p=0.024)$. They were also more likely to notify patients about the risks of radiation $(p=0.03)$. There was no difference between their behavior and the behavior of doctors who did not have formal training on radiation protection in the selection of imaging modalities for pregnant patients (Figure 3).

Discussion. The aim of this study was to assess the knowledge of radiation doses and risks among doctors working in the Emergency departments in the city of Jeddah, Kingdom of Saudi Arabia. Emergency department doctors are required to have adequate 
Table 3 - Answers to questions assessing knowledge of radiation risks ( $\mathrm{N}=171)$.

\begin{tabular}{|c|c|c|}
\hline Variables (Assessment area) & Choices & $(\%)$ \\
\hline \multicolumn{3}{|l|}{ Knowledge of the lifetime risk of cancer due to ionizing radiation } \\
\hline \multirow{2}{*}{$\begin{array}{l}\text { Do you think a one-time abdominal CT in childhood } \\
\text { increases the lifetime risk for cancer? }\end{array}$} & "Yes" & $65(38.9)$ \\
\hline & "No" & $102(61.1)$ \\
\hline \multicolumn{3}{|l|}{ Informing their patients about the risks of radiation: } \\
\hline \multirow{2}{*}{$\begin{array}{l}\text { When ordering a diagnostic radiological exam, do you } \\
\text { notify your patients about the potential side effects of } \\
\text { radiation before the examination? }\end{array}$} & "Yes" & $106(63.1)$ \\
\hline & "No" & $62(36.9)$ \\
\hline \multicolumn{3}{|l|}{ Selection of imaging modalities for pregnant patients: } \\
\hline \multirow{5}{*}{$\begin{array}{l}\text { When ordering a diagnostic radiological exam for a } \\
\text { pregnant patient: }\end{array}$} & "I never order a diagnostic radiological exam for a pregnant patient." & $59(35.3)$ \\
\hline & $\begin{array}{l}\text { "I follow the suggestions of the obstetrics and gynecology } \\
\text { department with regards to the orders I request." }\end{array}$ & $43(25.7)$ \\
\hline & $\begin{array}{c}\text { "I freely order any diagnostic radiological exam knowing there is no } \\
\text { side effect." }\end{array}$ & $4(2.4)$ \\
\hline & $\begin{array}{l}\text { "I order diagnostic radiological exams on pregnant patients as long as } \\
\text { she wears a lead vest and she is in the appropriate trimester for such } \\
\text { an exam." }\end{array}$ & $6(3.6)$ \\
\hline & $\begin{array}{l}\text { "I observe the pros and cons of such an exam, notify the patient } \\
\text { about the potential outcomes, and request a lead vest to be worn by } \\
\text { the patient before ordering a diagnostic radiological exam." }\end{array}$ & $55(32.9)$ \\
\hline \multicolumn{3}{|l|}{ Knowledge about risks on the fetus } \\
\hline \multirow{5}{*}{$\begin{array}{l}\text { Which one of the following radiological imaging modalities } \\
\text { carries the lowest risk for the fetus? }\end{array}$} & Chest CT & $62(36.9)$ \\
\hline & Abdominal $\mathrm{x}$-ray & $53(31.5)$ \\
\hline & Pelvic x-ray & $2(1.2)$ \\
\hline & Lumbar vertebrae $\mathrm{x}$-ray & $46(27.4)$ \\
\hline & Abdominal CT & $5(3.0)$ \\
\hline
\end{tabular}

knowledge because radiological investigations using ionizing radiation are increasingly used in the ED. In our study, the level of knowledge varied among participants, although we found that doctors working in an ED generally had a poor knowledge of radiation doses used in different imaging modalities and the risks associated with the imaging modalities. The average overall correct dose estimation rate was $20.8 \%$, which indicates that only one-fifth of the doses estimated by the participants were correct. Overall, doctors underestimated doses (28.6\%) more than they correctly estimated them or overestimated them. They also underestimated the risk of radiation. Both of these factors could result in an increased number of unnecessary investigations. This observation is consistent with findings in the existing literature which indicated that ED doctors were more likely to order radiological investigations because they were unaware of the doses and risks. ${ }^{1,2,7}$ However, in our study, most doctors preferred to answer "I don't know" instead of randomly guessing the correct doses, which may be a good sign that they realize their lack of knowledge and hence the necessity of receiving radiation protection training.
It was surprising to find that $55 \%$ of respondents were unaware that US has no ionizing radiation and $67 \%$ of respondents were unaware that MRI has also no ionizing radiation.

These percentages were significantly higher than those observed in other studies. , $2,5,7,10$ Our finding could be the result of the lack of radiation protection training because $80 \%$ of the participants in our study had no training. However, there was no significant difference in the overall dose estimation rate between these participants and those who had undergone training, particularly in US ( $p=0.4)$ and MRI dose estimation $(p=0.3)$. Consultants were more knowledgeable about radiation doses and lifetime cancer risk than were specialists and residents. This finding indicated that experience has a role in knowledge about radiation doses and risks. This statement is supported by evidence from a study conducted in Malaysia in which doctors who had 7 years or more of work experience answered more correctly than did doctors who had practiced less than 7 years $(p<0.05) .{ }^{10}$ By contrast, another study, which included 14 hospitals in Australia, showed a strong inverse relationship between years of experience and knowledge of radiation doses and risks: doctors 


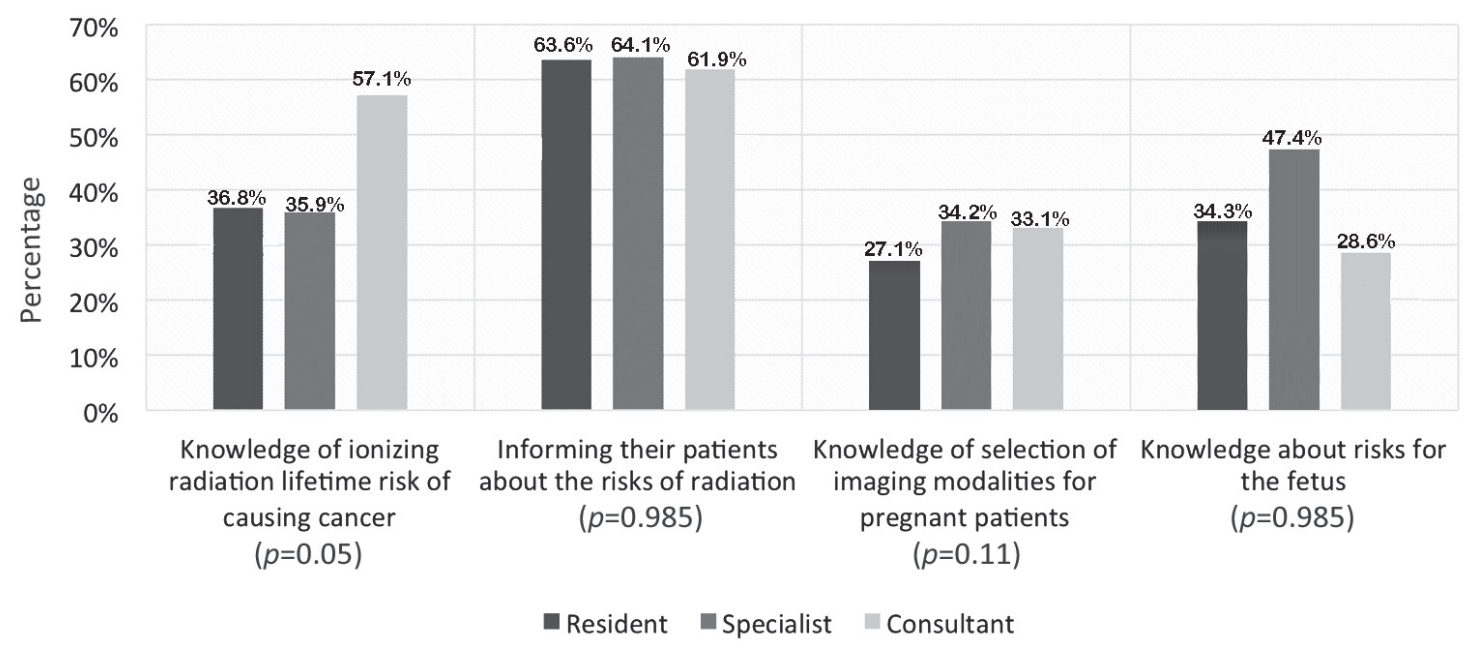

Figure 2 - Correct answer rate for questions assessing knowledge of risks by level of training.

with more than 15 years of experience were more likely to incorrectly estimate doses and recognize the risks. ${ }^{11}$ This finding was attributed to senior doctors possibly using an older convention (namely, frontal and lateral chest $\mathrm{x}$-ray views) to calculate relative doses, as opposed to the current convention of using a single frontal chest $\mathrm{x}$-ray image. Emergency physicians had a higher correct dose estimation rate than did physicians from other specialties, whereas pediatricians had a relatively lower rate. This observation is similar to that described in a study by Brown et al. ${ }^{12}$ This finding is alarming because pediatric patients have an increased sensitivity to radiation; therefore, pediatricians should particularly have a high level of knowledge about radiation doses and their effects.

Overall, $63.1 \%$ of respondents reported discussing the potential risks of radiation exposure with patients before ordering an examination; this proportion is higher than those reported in previous studies. ${ }^{1,6}$ However, we believe this percentage should be higher, and doctors should be more keen on empowering patients to allow them to make informed choices about their healthcare needs. In addition, discussing risks with parents improves parental perception of radiation-induced risk and reduces parental refusal of investigations requested by their physicians. ${ }^{13}$ Physicians who do not discuss risks with patients could argue that, in an emergency setting, the need for radiological investigations is mostly clear, and they only discuss the risks when the reason for an examination is borderline or questionable. Doctors who had radiation protection training answered 3 of 4 questions related to radiation risks significantly more correctly than those who did not have training. This finding may emphasize the significance of training. Despite this training, their level of knowledge remains inadequate.

To overcome this lack of knowledge, several measures can be taken. First, mandatory curricula on the effects and risks of radiation should be implemented early in medical schools. Graduates should then be mandated to take such courses regularly to be up to date regarding this matter. Furthermore, establishing a collaboration between EDs and radiology departments to create local protocols for when to order radiological investigations and what to order is one method that can increase the awareness among emergency doctors and decrease unnecessary investigations. It has also been suggested that providing radiation doses and risks on the imaging order form would allow the ordering doctor to consider discussing risks with patients. ${ }^{14}$ Mandating doctors to sign that they have informed patients about the risks of an examination and that the patients gave consent could also be beneficial. Including a patient's total accumulated dose of radiation on the formal radiology report, which is already practiced in several United Kingdom hospitals. ${ }^{15}$ It would be a good educational tool for readers, as well as a reminder not to subject patients to unnecessary doses of radiation. It is important to mention that the utilization of dose monitoring software and the establishment of diagnostic reference levels (DRLs) helped in acquiring data on patients' radiation exposure for benchmarking and further dose reduction. ${ }^{16}$ Reference guidelines were jointly created by the American college of radiology (ACR), American association of physicists in 


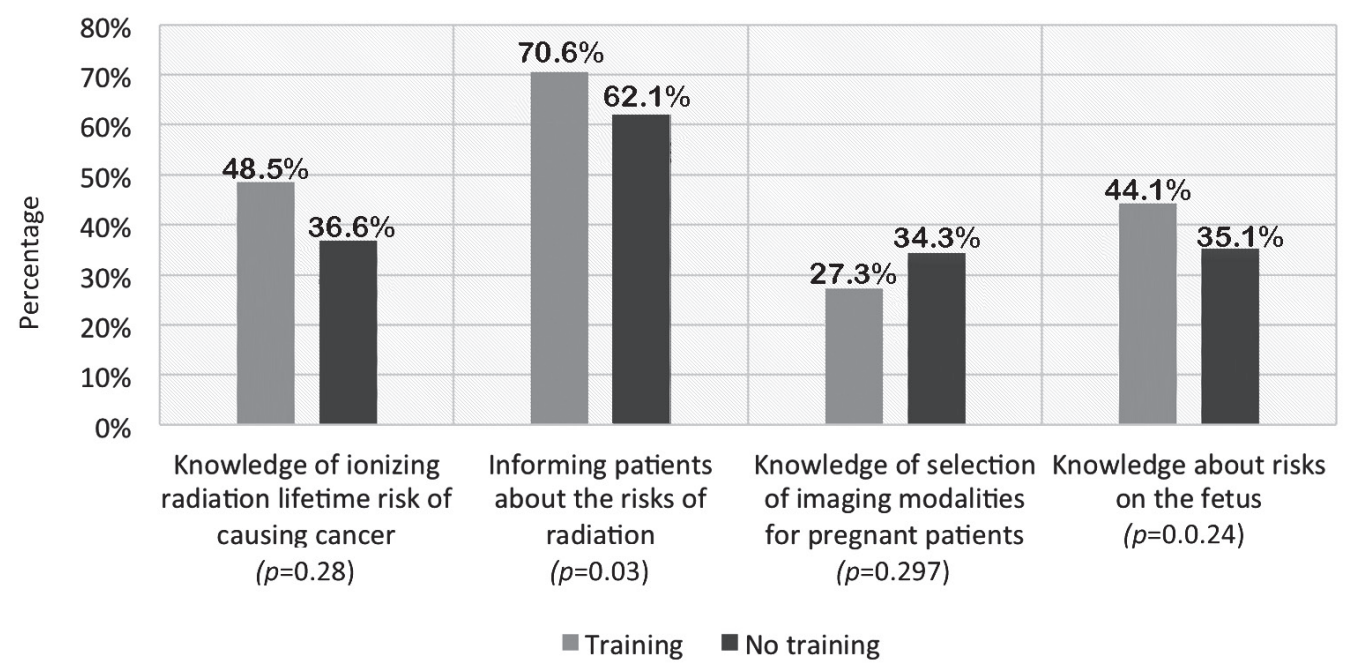

Figure 3 - The correct answer rate for questions assessing knowledge of risks, based on whether physicians had or had not received formal training on radiation protection.

medicine (AAPM), and national council on radiation protection and measurements (NCRP). The Bonn Call for Action, which is a joint statement by the world health organization (WHO) and the international atomic energy association (IAEA), also emphasizes the importance of DRLs as a mean to decrease unnecessary exposure to patients and to raise awareness among healthcare professionals. ${ }^{17}$ Several other publications have also concluded the same. ${ }^{18,19}$ In Kingdom of Saudi Arabia, the Saudi food and drug authority (SFDA), which is the regulatory body for diagnostic imaging facilities, published new policies and regulations in 2017 that adhere to the Bonn Call for action. ${ }^{20}$ However, the development of a national diagnostic reference level (NDRL) is necessary. Therefore, the national radiation protection committee, was established and the NDRL project was started. This project will hopefully further aid in dose optimization and increase the awareness among healthcare workers.

Study limitations. The main limitation is that the study included more junior doctors than senior doctors. It is possible that this factor led to the poorer overall level of knowledge. In addition, the number of respondents from individual specialties other than emergency medicine was small, which could have resulted in responses that were not representative of the specialty. The small number of representatives from private hospitals and secondary care hospitals is the reason we did not compare the performance of doctors working in the ED of secondary care hospitals with that of doctors working in tertiary care hospitals, or compare the performance of ED doctors working in private hospitals with that of doctors working in public hospitals. In our study, we evaluated knowledge by asking participants to quantitatively estimate doses, whereas Krille et al, ${ }^{5}$ in their systemic review reported that knowledge about the radiation doses did not necessarily imply fewer CT requests by doctors. Krille also recommended that it could be more appropriate to assess knowledge by asking about primary examinations and giving specific case scenarios. ${ }^{5}$ However, there are dose-related risks with radiological investigations; hence, doctors must be aware of the doses and attempt to decrease performing unnecessary studies. Future large-scale studies should be conducted to examine whether knowledge of CT and $\mathrm{x}$-ray doses actually decreases the number of radiological investigations orders using ionizing radiation.

In conclusion, The value of CT and x-ray imaging in patient care is undisputed. However, it should always be borne in mind the various risks resulting from such examinations. In addition, radiological investigations should only be used when the benefit outweighs the risk. This study demonstrated that doctors working in an ED had poor knowledge about the radiation doses received by their patients, and poor knowledge about the risks associated with the radiation exposure. This issue warrants attention considering the increasing use of radiological investigations. Several measures that may aid in increasing their level of knowledge and decreasing the number of unnecessary studies have been proposed. These measures include implementing radiation protection curricula early in medical schools, mandating regular radiation protection training for doctors, 
creating local protocols for ordering examinations, and including patient's accumulated doses of radiation on the formal radiology report.

\section{References}

1. Günalp M, Gülünay B, Polat $O$, Demirkan A, Gürler S, Akkaş $\mathrm{M}$, et al. Ionising radiation awareness among resident doctors, interns, and radiographers in a university hospital emergency department. Radiol Med 2014; 119: 440-447.

2. Keijzers GB, Britton CJ. Doctors' knowledge of patient radiation exposure from diagnostic imaging requested in the emergency department. Med J Aust 2010; 193: 450-453.

3. Griffey RT, Jeffe DB, Bailey T. Emergency physicians' attitudes and preferences regarding computed tomography, radiation exposure, and imaging decision support. Acad Emerg Med 2014; 21: 768-777.

4. Tsiridis E, Lusty PJ, Narvani AA, Tsapakis EM. Doctors' knowledge of exposure to ionising radiation: doctors' exposure to ionising radiation may be cause for concern. BMJ 2003; 327: 1167.

5. Krille L, Hammer GP, Merzenich H, Zeeb H. Systematic review on physician's knowledge about radiation doses and radiation risks of computed tomography. Eur J Radiol 2010; 76: 36-41.

6. Soye JA, Paterson A. A survey of awareness of radiation dose among health professionals in Northern Ireland. Br J Radiol 2008; 81: 725-729.

7. Lee WJ, Woo SH, Seol SH, Kim DH, Wee JH, Choi SP, et al. Physician and nurse knowledge about patient radiation exposure in the emergency department. Niger J Clin Pract 2016; 19: 502-507.

8. The 2007 Recommendations of the International Commission on Radiological Protection. ICRP publication 103. Ann ICRP 2007; 37: 1-332.

9. United Nations Scientific Committee on the Effects of Atomic Radiation (UNSCEAR). Sources and effects of ionizing radiation. Vol 1. New York (NY): UNSCEAR; 2008.

10. Arslanoğlu A, Bilgin S, Kubal Z, Ceyhan MN, Ilhan MN, Maral I. Doctors' and intern doctors' knowledge about patients' ionizing radiation exposure doses during common radiological examinations. Diagn Interv Radiol 2007; 13: 53-55.
11. Kew TY, Zahiah M, Zulkifli SZ, Noraidatulakma A, Hatta S. Doctor's knowledge regarding radiation dose and its associated risks: cross-sectional study in a tertiary hospital in Malaysia. Hong Kong J Radiol 2012; 15: 71-79.

12. Brown N, Jones L. Knowledge of medical imaging radiation dose and risk among doctors. J Med Imaging Radiat Oncol 2013; 57: 8-14.

13. Larson DB, Rader SB, Forman HP, Fenton LZ. Informing parents about CT radiation exposure in children: it's $\mathrm{OK}$ to tell them. AJR Am J Roentgenol 2007; 189: 271-275.

14. Jacob K, Vivian G, Steel JR. X-ray dose training: are we exposed to enough? Clin Radiol 2004; 59: 928-934; discussion 926-927.

15. Grove ML. Doctors' knowledge of exposure to ionising radiation: just tell them the dose. BMJ 2003; 327: 1166.

16. Committee 3 of the International Commission on Radiological Protection (ICRP). Diagnostic reference levels in medical imaging: review and additional advice [Internet]. ICRP; 2002 [Accessed Dec 10, 2018]. Available from: http://www.icrp.org/ docs/DRL_for_web.pdf

17. International Atomic Energy Agency (IAEA). Bonn Call to Action: 10 actions to improve radiation protection in medicine in the next decade [Internet]. World Health Organization (WHO); 2012 [Accessed December 2012]. Available from: https://www.iaea.org/sites/default/files/17/12/bonn-call-foraction.pdf

18. Heilmaier C, Zuber N, Bruijns B, Weishaupt D. Does Real-Time Monitoring of Patient Dose With Dose Management Software Increase CT Technologists' Radiation Awareness? AJR Am J Roentgenol 2016; 206: 1049-1055.

19. Frush D, Denham CR, Goske MJ, Brink JA, Morin RL, Mills TT, et al. Radiation protection and dose monitoring in medical imaging: a journey from awareness, through accountability, ability and action...but where will we arrive? J Patient Saf 2013; 9: 232-238.

20. Saudi Food and Drug Authority (SFDA). SFDA requirements for radiological health: safe practice in health facilities [Internet]. SFDA; 2016 [Accessed Dec 10, 2018]. Available from: https://www.sfda.gov.sa/ar/medicaldevices/regulations/ Documents/4.Ar.Eng.pdf 
A prospective study of 8 EDs ... Barnawi et al

Appendix 1 - Effective doses of radiation for different radiological modalities compared to chest $\mathrm{x}$-ray and the range of knowledge on doses received by patients that were considered acceptable.*

\begin{tabular}{lccc}
\hline $\begin{array}{l}\text { Diagnostic imaging } \\
\text { modality }\end{array}$ & $\begin{array}{c}\text { Effective } \\
\text { dose }(\mathrm{mSv})\end{array}$ & $\begin{array}{c}\text { Equivalent number } \\
\text { of chest x-rays } \\
\text { resulting in the } \\
\text { same effective dose }\end{array}$ & $\begin{array}{c}\text { Following ranges are } \\
\text { accepted (based on } \\
\text { equivalent number } \\
\text { of chest x-rays) }\end{array}$ \\
\hline Chest x-ray & 0.02 & 1 & 1 \\
Cranial x-ray & 0.07 & 3.5 & $0-10$ \\
Pelvic x-ray & 0.7 & 35 & $10-50$ \\
Abdominal x-ray & 0.7 & 35 & $10-50$ \\
Cranial CT & 2.4 & 120 & $50-200$ \\
Chest CT & 7.8 & 390 & $200-500$ \\
Abdominal CT & 12.0 & 600 & $>500$ \\
Pelvic CT & 10.5 & 525 & $>500$ \\
Abdominal US & 0 & 0 & 0 \\
Abdominal MRI & 0 & 0 & 0 \\
\hline
\end{tabular}

Copyright permission from United Nations Scientific Committee on the Effects of Atomic Radiation (UNSCEAR). Sources and effects of ionizing radiation. Vol 1. New York (NY): UNSCEAR; 2008. ${ }^{10}$ 